\title{
Tinggalan Arkeologi di Pura Subak Ulun Suwi Sidewaas, Bangli
}

\author{
Ida Bagus Gd Panji Semara1, A.A. Gde Aryana², Coleta Palupi Titasari ${ }^{3}$ \\ ${ }^{[123]}$ Prodi Arkeologi, Fakultas Ilmu Budaya, Universitas Udayana \\ 1(panjismara45@yahoo.com), ${ }^{2}$ (arkeologi_unud@yahoo.co.id), ${ }^{3}$ (anjunary@yahoo.com) \\ *Corresponding Author
}

\begin{abstract}
Abstrak
Arca merupakan salah satu peninggalan masa klasik yang memiliki beragam bentuk dan merupakan perkembangan pemikiran manusia dalam bidang kesenian maupun kebudayaan. Pemikiran tersebut dapat dilihat pada arca di Pura Subak Ulun Suwi Sidewaas Bangli yang sampai sekarang masih difungsikan dengan arca yang berjumlah 14 buah. Beberapa permasalahan dalam penelitian ini meliputi bentuk, fungsi serta makna tinggalan arkeologi di Pura Subak Ulun Suwi Sidewaas Bangli. Penelitian ini menggunakan metode pengumpulan data yang terdiri dari beberapa tahap yaitu observasi, wawancara, dan studi pustaka. Tahap selanjutnya merupakan tahap analisis data, tahap ini menggunakan analisis kualitatif dan analisis ikonografi. Teori yang digunakan dalam penelitian ini adalah teori fungsional dan teori semiotika, yang diharapkan mampu memecahkan permasalahan dalam penelitian ini. Tinggalan arkeologi di Pura Subak Ulun Suwi Sidewaas Bangli ini meliputi dua arca perwujudan bhatari, empat arca perwujudan bhatara, satu lingga tribahga, dua lingga diatas lapik dan stela serta lima fragmen arca.Tingalan-tingalan tersebut dipercayai sebagai suatu sarana untuk memohon kesejahteraan bagi tumbuh-tumbuhan yang menjadi penghasilan bagi masyarakat yang bergantung pada hasil perkebunan (tegalan). Air suci yang didapat dari pura selain digunakan untuk keperluan diri sendiri, namun juga digunakan untuk kesuburan ternak dan tumbuh-tumbuhan. Tinggalan yang dikeramatkan oleh masyarakat penyungsung pura mempunyai makna sebagai suatu sarana pemujaan, sarana pemujaan yang dimaksud merupakan simbolis dari dewa dewi ataupun leluhurnya dalam upaya mendekatkan diri pada para leluhurnya.
\end{abstract}

Kata kunci :arca, Sidewaas, bentuk, fungsi, makna

\begin{abstract}
Arca is one of the relics of the classical period that has various forms and is the development of human thought in the field of art and culture. Thought can be seen in Pura Subak Ulun Suwi Sidewaas Bangli which until now still functioned with the statue which amounted to 14 pieces. Some of the problems in this study include the form, function and meaning of archaeological remains in Pura Subak Ulun Suwi Sidewaas Bangli. This study uses data collection methods consisting of several stages of observation, interviews, and literature study. The next stage is the stage of data analysis, this stage using qualitative analysis and iconography analysis. The theory used in this research is the functional theory and the theory of semiotics, which is expected to solve the problems in this research. Archeology in Pura Subak Ulun Suwi Sidewaas Bangli encompasses two statues of bhatari embodiment, four statues of bhatara, one lingga tribhaga, two lingga above lapel and stela and five fragments of the statue. These stalks are believed to be a means to invoke the welfare of the plants that are incomes for the people who depend on the plantations. The holy water obtained from the temple is not only used for self-use, but also used for the fertility of cattle and
\end{abstract}


plants. The residue that is sanctioned by the community of temple penyungsung has meaning as a means of worship, the worship means in question is symbolic of the goddess god or his ancestor in an effort to get closer to his ancestors.

Keywords: statue, Sidewaas, shape, function, meaning

\section{Latar Belakang}

Peninggalan arkeologi merupakan hasil budaya dari nenek moyang yang tidak ternilai harganya, apabila ditinjau pada masa sekarang, maka hasil ciptaan budaya masa lalu dapat digunakan sebagai cerminan dalam berprilaku dan berusaha dalam memahami nenek moyang pada masa lampau, maka akan muncul suatu pemikiran yang positif dengan penghargaan terhadap kepandaian yang telah dimilki oleh nenek moyang (Prawirajaya, 2012:1-2).

Benda-benda manusia masa lampau merupakan salah satu bentuk dalam menentukan tingkat pengetahuan manusia masa lampau melalui banyak atau sedikitnya hasil kebudayaan yang ditinggalkan pada masa tersebut. Dengan kata lain, pengetahuan manusia pada masa lalu berkembang setahap demi setahap mengikuti alur perkembangan jaman pada masa lampau, sehingga kemungkinan banyak hasil karya yang telah diciptakan yang memiliki keunikan ataupun nilai seni yang tinggi. Bali memiliki adat istiadat, seni budaya maupun tinggalan arkeologi yang masih terjaga keasriannya (Ardana, 1977:1).

Tinggalan arkeologi di Bali berupa benda-benda hasil kebudayaan manusia masa lampau yang memiliki rentetan perjalanan yang panjang dari masa prasejarah hingga klasik, sehingga banyak perkembangan yang telah terjadi pada benda-benda hasil kebudayaan masa lampau. Namun kenyataan yang kita lihat dilapangan sekarang ini adalah banyaknya tinggalan arkeologi memiliki sifat yang terbatas baik dari segi jumlah ataupun kemampuan dalam mengungkap kegiatan manuasia pada masa lampau (Srijaya, 1988:1-2).

Tinggalan arkeologi di Bali, baik yang berasal dari zaman prasejarah maupun klasik tidak semuanya mendapatkan .perawatan yang baik dan memadai, padahal semakin lama peninggalan seni budaya tersebut tidak mendapatkan perawatan, maka akan cepat mengalami kerusakan yang disebabkan oleh faktor cuaca dan iklim di daerah tropis, untuk itu sangat perlu diadakan penelitian secara bertahap.Maka dari itu perlu adanya kesadaran dari masyarakat dan instansi terkait untuk saling membantu dalam menjaganya. salah satu peninggalan terpenting di Bali adala harca.

Arca adalah benda peninggalan manusia masa lampau yang diwujudkan dalam bentuk patung. Arca merupakan hasil kebudayaan manusia masa lampau yang menempati kedudukan jenis patung yang paling lama ada jika dilihat dari segi usia. Dengan kata lain, bahwa arca merupakan salah satu sarana yang digunakan sebagai media pemujaan di Bali(Linus, 1985:1).

Pemujaan kepada tinggalan arkeologi sebagai simbolis dari roh nenek moyang masih di lakukan di Bangli. Tinggalan tersebut pada umumnya tersimpan di tempat-tempat suci yang disungsung dan dikeramatkan oleh masyarakat pendukungnya. Menurut anggapan mereka benda-benda tersebut dapat memenuhi kebutuhan religi, sehingga dapat dikatakan hasil kebudayaan manusia masa lalu yang ditemukan dan dipelihara hingga saat ini tetap difungsikan dalam kehidupan masyarakat sekitarnya, hal tersebut dapat 
kita lihat pada tinggalan arkeologi di Pura Subak Ulun Suwi Sidewaas Bangli yang hingga sekarang masih dimanfaatkan untuk kegiatan yang bersifat keagamaan oleh masyarakat disekitar tersebut.

Menurut masyarakat penyungsung pura, tinggalan arkeologi di Pura Subak Ulun Suwi Sidewaas Bangli sudah ada sejak dari dulu. Penemuan salah satu tinggalan yang berada pada tegalan milik warga subak yang berada di sebelah barat pura menjadi bukti bahwa areal Subak Sidewaas merupakan tempat yang mempunyai tinggalan sejarah yang masih tersimpan. Selain itu terdapat juga cerita masyarakat tentang daerah subak Sidewaas

Berdasarkan uraian diatas, penulis tertarik meneliti tinggalan arkelogi di Pura Subak Ulun Suwi Sidewaas Bangli, selainkarena belum pernah ada yang meneliti,juga dikarenakansifatdata yang terbatas dan rentan mengalami kerusakan sehingga dapat menghilangkan bentuk, fungsi, dan makna yang terkandung didalam tinggalan tersebut, maka sangat perlu diteliti.

\section{Pokok Permasalahan}

1) Apakah fungsi tinggalan arkeologi yang ada di Pura Subak Ulun Suwi Sidewaas Bangli?

2 Apakah makna tinggalan arkeologi yang ada di Pura Subak Ulun Suwi Sidewaas Bangli?

\section{Tujuan Penelitian}

a) Mengetahu ifungsi tinggalan arkeologi di Pura Subak Ulun Suwi Sidewaas Bangli, baik dimasa lalu maupun sekarang,

b) Mengetahui makna tinggalan arkeologi di Pura Subak Ulun Suwi Sidewaas Bangli.

\section{Metode Penelitian}

Jenis penelitian yang dipakai dalam penelitian ini adalah pendekatan secara kualitatif. Pendekatan yang dilakukan ini merupakan suatu tahapan kegiatan untuk mengkaji suatu aktivitas atau penelitian yang menghasilkan data secara deskriptif dalam bentuk kata-kata, tulisan dan bahasa. Proses penelitian yang dilakukan di Pura Subak Sidewaas ini bersifat siklus, dimana penelitian ini dilakukan secara terus menerus dilakukan kepada objek sehingga hasil yang didapatkan bisa di katakan maksimal.

Penelitian ini menggunakan Beberapa teori seperti, teori fungsional yang digunakan untuk memecahkan permasalahan mengenai fungsi dari tingalan di Pura Subak Ulun Suwi Sidewaas Bangli, setra teori semiotika yang digunakan untuk memecahkan permasalahan makna tinggalan arkeolog idi pura Subak Ulun Suwi Sidewaas Bangli.

Penelitian ini menggunakan beberapa teknik analisis untuk mengolah data yang didapatkan. Beberapa analisis yang digunakan seperti analisis kualitatif dan analisis ikonografi. Analisis kualitatif ini memiliki tujuan untuk mengetahui jenis penelitian tentang riset yang bersifat deskriptif. Landasan teori dimanfaatkan sebagai pemandu agar penelitian sesuai dengan fakta di lapangan. Analsisi kualitatif dilakukan dengan cara memilah-milah, menglompokan, mengurut dan mengatur data menjadi satuan data yang dapat dikelola untuk menemukan apa yang dianggap penting dan dapat dipelajari, serta nantinya dapat memberikan gambaran tentang penelitian yang dilakukan. Analisis ini digunakan dalam memecahkan fungsi dan makna tinggalan arkeologi di Pura Subak Ulun Suwi Sidewaas Bangli 


\section{Hasil dan Pembahasan}

Tinggalan arkeologi di Pura Subak Ulun Suwi Sidewaas Bangli bejumlah 14 buah yang terdiri dari enam buah arca perwujudan, tiga buah lingga dan lima buah fragmen arca yang diletakan di dua buah pelinggih yaitu pelinggih Giri Putri dan pelinggih Betara Siwa.

\subsection{Fungsi tinggalan Arkeologi di Pura Subak Ulun Suwi Sidewaas, Bangli \\ a. Arca Perwujudan}

Untuk mengetahui fungsi arca perwujudan Bhatara dan Bhatari di Pura Subak Ulun Suwi Sidewaas Bangli, perlu diuraikan fungsi secara umum arca perwujudan Bhatara dan Bhatari. Drs. I Ketut Linus mengemukakan pendapatnya tentang pengertian arca beliau mengetakan bahwa dalam Ilmu arkeologi yang disebut dengan arca adalah sebuah patung (Linus, 1985:1). Patung adalah suatu benda perwujudan yang memiliki bentuk tiga dimensi dalam ukurannya yang besar maupun kecil, dengan kata lain patung tersebut dibuat dengan sedetail mungkin dan dapat dilihat dari berbagai arah.

Pada dasarnya arca perwujudan itu dibuat dalam rangka keagamaan, dan nantinya akan dipakai sebagai tempat suci untuk roh-roh leluhur yang telah meninggal. Melalui arca perwujudan ini, diharapkan roh-roh leluhur atapun nenek moyang berkenan untuk turun dan nantinya dapat menjadi media penghubung antara roh leluhur dan keturunannya. arca perwujudan adalahsalah satu sarana dalam mendekatkan diri kepada roh nenek moyang yang telah berjasa dalam kehidupan kita.

Begitu pula fungsi arca perwujudan di Pura Subak Ulun Suwi Sidewaas Bangli pada masa lalau adalah sebagai media pemujaan dan penghormatan kepada roh suci seorang raja yang pernah berkuasa dan dianggap membawa kedamaian bagi masyarakatnya. Melalui ritus-ritus pemujaan baik dalam bentuk arca menandakan adanya kebersamaan baik dari segi sikap, pangaruh budaya, agama, maupun kepercayaan sehingga memperkuat hubungan antara masyarakat dan pemimpinnya pada masa itu. Hubungan tersebut dapat kita lihat pada pembuatan arca-arca para raja yang dulu pernah berkuasa di jawa yang bercirikan dengan atribut-atribut dewa yang dianggap penitisnya atau sesuai sikap dari raja yang pernah memimpin yang bertujuan mengukuhkan kekuasaannya (Sugitawan, 2003:72).

Fungsi arca bhatara maupun bhatari di Pura Subak Ulun Suwi Sidewaas Bangli pada masa sekarang dapat dikatakan bahwa arca-arca tersebut masih tetap difungsikan dan dikeramatkan oleh masyarakat penyungsungnya. Hal tersebut diketahui dari padaa saat observasi yang dilakukan di pura tersebut, arca-arca perwujudan bhatara dan bhatari tidak boleh diturunkaan sembarang orang, karena hanya orangorang tertentu yang diperbolehkan.

Pada saat piodalan di pura Pura Subak Ulun Suwi Sidewaas Bangli, jika piodalannya berlangsung besar, maka arca-arca bhatara akan diturunkan untuk dirias dan dihaturkan sesajen. Namun jika hanya dilakukan selama satu hari, arca-arca akan tetap pada tempat penyimpannya, namun hanya diaturkan sesajen. Pada saat Piodalan inilah semua masyarakat subak mengadakan persembahyangan bersama, dan juga melakukan pemujaan kepada arca-arca tersebut. Pemujaan dilakukan dengan tujuan untuk memohon keselamat dan kesejahteraan bagi masyarakat subak, selain itu pemujaan dilakukan agar diberi keseburan bagi tumbuh-tumbuhan yang menjadi penghasilan bagi masyarakat yang bergantung hasil tegalan. Tirta yang didapat dari pura selain digunakan untuk keperluan diri sendiri, namun juga 
digunakan untuk kesuburan ternak dan tumbuh-tumbuhan (wawancaradengan Ida Bagus Gd Suartama selaku kelihan subak dan Pemangku Pura).

\section{b. Lingga}

Lingga dapat diartikan juga sebagai perwujudan dari dewa Siwa sebagai sebuah Phallus atau alat kelamin lakilaki. Umumnya lingga sering ditempatkan pada atas yoni yang merupakan gambaran dari alat kelamin wanita. Fungsi lingga secara umum adalah melambangkan suatu kesuburan (Linus dalam Adri, 1990: 69).

Tinggalan arkeologi berupa lingga di Pura Subak Ulun Suwi Sidewaas Bangli berjumlah tiga buah yang tersimpan di pelinggih giri putri. Adapun Ketiga lingga tersebut sebuah lingga tribhaga tanpa stela maupun lapik dan dua buah lingga tribhaga dengan stela dan lapik. Ketiga lingga tersebut oleh masyarakat penyungsung pura masih memiliki fungsi, dilihat dari pemanfaatan tinggalan tersebut yang sampai sekarang masih dipakai sebagai media pemujaan untuk memohon keselamatan bagi masyarakat dan juga diberikana perlindungan kesuburan bagi hewan ternak maupun tegalan supaya mendapatkan hasil yang melimpah (wawancara dengan Ida Bagus Gd Suartama selaku kelihan subak dan Pemangku Pura).

\section{c. Fragmen Arca}

Tinggalan lain selain arca perwujudan dan lingga di Pura Subak Ulu Suwi Sidewaas Bangli, terdapat juga fragmen-fragmen arca yang sampai sekarang masih tersimpan di Pura tersebut. Fragmen yang dimaksudkan adalah kumpulan batu-batu padas yang memiliki bentuk seperti badan arca dengan kepalanya dan terdapat juga bagian badan tanpa kepala. Fragmen arca yang terdapat di Pura Subak Ulun Suwi Sidewaas Bangli memiliki dua bentuk yaitu fragmen arca dagian kepala hingga badan dan fragmen arca dari bagian pinggang hingga bagian kaki. Keseluruhan fragmen arca yang terdapat di Pura ini masih disakralkan dan difungsikan sebagai salah satu sarana pemujaan dengan diletakan pada dua bangunan Suci Pelinggih Giri Putri dan Pelinggih Bhetara Siwa.

Dewasa ini tinggalan arkeologi yang terdapat di Pura Subak Ulun Suwi Sidewaas Bangli menurut penuturan dari pemangku dan kelihan pura, bahwa tinggalan di pura tersebut merupakan warisan dari para leluhur pedahulu yang harus dijaga dan dihormati. Dapat kita ketahui bahwa tinggaan arkeologi di Pura Subak Ulun Suwi Sidewaas Bangli memiliki fungsi sebagai media pemujaan kepada roh leluhur ataupun pendahulu untuk memohon keselamatan, perlindungan, kesejahteraan dan kesuburan bagi diri sendiri, keluarga, hewan peliharaan dan juga tumbuhtumbuhan.

Berkaitkan dengan fungsi dari Pura Subak pada umumnya, dimana Pura Subak sebagai tempat untuk memuja kekuatan Tuhan Hyang Maha Esa dalam manifestasinya sebagai Dewi Sri ( Dewi Kesuburan), namun juga sebagai tempat memuja dan memuji kebesaran dari Tuhan Hyang Maha Esa dalam manifestasinya sebagai Dewa Wisnu ( karena untuk di Bali, Subak Identik dengan sistem pengairan di sawah)yang bertugas untuk memelihara alam semesta (Soebandi dalam Prayudi, 2016 : 103).

\subsection{Makna tinggalan Arkeologi di Pura Subak Ulun Suwi Sidewaas, Bangli}

Tinggalan Arkeologi di Pura Subak Ulun Suwi Sidewaas Bangli pada dasarnya sama dengan Pura lainnya di bali. Tinggalan di Pura ini digunakan sebagai media pemujaan kepada Tuhan Hyang Maha Esa dalam manifestasinya sebagai Dewa/Dwi Kesuburan.Tuhan 
sebagai Maha pencipta dan Maha segalanya dalam upaya untuk memuja kemahakuasaan beliau sangatlah sulit untuk bisa membayangkan terlebih lagi untuk dipikirkan, oleh karena itu umat membuat benda ataupun alat untuk dijadikan spirit untuk menuju padawujudnya. Adapun Benda atau alat yang menjadi simbol dalam memuja kemahakuasaan Tuhan di Pura Subak Ulun Suwi Sidewaas Bangli adalah tinggalan Arkeologi yang berupa arca perwujudan bhatara dan bhatari, lingga dan fragmen arca.

Masyarakat setempat memohon kesuburan di Pura ini pada saat Piodalan, Rahina Purnama, dan tumpek Landep, pada saat ini lah semua masyarakat subak mengadakan persembahyangan bersama, dan juga melakukan pemujaan kepada Tinggalan arkeologi tersebut.

Tirta yang didapat dari pura selain digunakan untuk keperluan diri sendiri, juga dilukatkan ternak dan tumbuhan. Adanya kepercayaan tersebut ditengah masyarakat Subak Sidewaas membuat tinggalan tersebut dimaknai sebagai benda yang memberikan dan mendatangkan kesuburan bagi ladang, hewan dan masyarakat subak (wawancaradengan Ida Bagus Gd Suartama selaku kelihan subak dan Pemangku Pura).

\section{Simpulan}

Berdasarkan pembahasan di atas, dapat ditarik simpulan sebagai berikut, yaitu :

a. Fungsi tinggalan arkeologi di Pura Subak Ulun Suwi Sidewaas Bangli pada masa lampau memiliki fungsi yang berbeda sesuai dengan bentuk dari masing-masing arca. Arca perwujudan bhatara dan bhatari pada masa lampau memiliki fungsi sebagai perwujudan dari tokoh seorang raja atau tokoh yang disegani yang pernah berkuasa dan meninggal untuk memohon perlindungan dan memohon kesejahteraan bagi masyarakatnya. Lingga memiliki fungsi sebagai media pemujaan terhadap dewa siwa yang merupakan simbol atau lambang dari suatu kesuburan. Tinggalan arkeologi di Pura Subak Ulun Suwi Sidewaas Bangli sampai masa sekarang masih dipuja dan dikeramatkan oleh penyungsungnya. Menurut masyarakat subak yang dominan adalah penyungsung pura tersebut, bahwa tinggalan-tinggalan tesebut memiliki kekuatan religius yang menjadi satu dengan pura tersebut. Tingalantingalan tersebut oleh masyarakat dipercayai sebagai salah satu sarana untuk memohon kesejahteraan bagi tumbuh-tumbuhan yang menjadi penghasilan bagi masyarakat yang bergantung hasil perkebunan (tegalan). Selain itu, tirta yang didapat dari pura selain digunakan untuk keperluan diri sendiri, namun juga digunakan untuk ternak dan tumbuhtumbuhan agar mendapatkan keselamatan dari segala penyakit dan hama.

b. Makna Kesuburan dari tinggalan arkeologi di Pura Subak Ulun Suwi Sidewaas Bangli yaitu sebagai suatu tinggalan yang dikeramatkan oleh masyarajkat penyungsung pura sebagai suatu sarana pemujaan. Sarana pemujaan yang dimaksud adalah tinggalan arkeologi tersebut merupakan simbolis dari dewa dewi ataupun leluhurnya dalam upaya mendekatkan diri pada para leuluhurnya. Selain itu, tinggalan 
arkeologi sebagai simbol kesuburan dari masyarakat Subak Sidewaas.

\section{DaftarPustaka}

Ardana, I Gusti Gede. 1971. Pengertian Pura di Bali. Proyek Pengembangan dan Pemeliharaan Kebudayaan Daerah Bali.

Adri, Gusti Nyoman.1990. "Seni Arca diPura Wongaya Desa satra Kintamani Bangli (Suatu Kajian Ikonografi)". Skripsi. Denpasar. Fakultas Sastra Universitas Udayana

Linus, Drs. I Ketut . 1985. Beberapa Patung Dalam Agama Hindu (pendekatan dari segi Arkeologi). Denpasar.

Prawirajaya, Kadek Dedy. 2012. "ArcaArca Kuna di Pura Sembung Sombangan Kecamatan Mengwi, Kabupaten Badung : Kajian Fungsi, Makna dan Periodisasi".Skripsi. Univesitas Udayana

Prayudi, Putu Agus Weda. 2016. "Tinggalan Arkeologi di Pura Puseh lan Bale Agung Tampuagan, Kecamatan Tembuku, Kabupaten Bangli ". Skripsi. Univesitas Udayana

Srijaya, I Wayan. 1988. "Dua Buah Arca Ganesa di atas Yoni di Pura Bole Gianyar Suatu Kajian konografis". Denpasar: Universitas Udayana

Sugitawan, Resud. 2003. ”Arca Bhatara Bhatari di Pura Saab Nusa Penida, Kabupaten Klungkung". Skripsi. Univesitas Udayana 